\title{
Perception and preferences of second professional undergraduate medical students for pharmacology teaching: a questionnaire based cross-sectional study
}

\author{
Jeetendra Kumar*, Mrityunjay K. Pandit, Piyush Anand, Brajesh Kumar
}

Department of Pharmacology, JLN Medical College, Bhagalpur, Bihar, India

Received: 28 July 2021

Accepted: 13 August 2021

*Correspondence:

Dr. Jeetendra Kumar,

Email: drjktkhag2003@gmail.com

Copyright: ( $)$ the author(s), publisher and licensee Medip Academy. This is an open-access article distributed under the terms of the Creative Commons Attribution Non-Commercial License, which permits unrestricted non-commercial use, distribution, and reproduction in any medium, provided the original work is properly cited.

\section{ABSTRACT}

Background: Feedback from students provides an opportunity to assess lacunae in current systems of teaching and forms the basis for framing desired modifications in the teaching methodology to enhance the magnitude of learning. This study was undertaken to know the views of students on current methodology of pharmacology teaching and to delineate the required changes to be made in it.

Methods: The questionnaire based cross-sectional study was conducted on 167 students of second professional undergraduate medical students. The questionnaire was divided in 2 different parts. Part A consisted 20 multiple choice questions on perception and preferences of students for pharmacology teaching and opinion on changes to be made was taken in the part B of the questionnaire.

Results: Pharmacology was marked as one of the most interesting and useful subjects by $49.1 \%$ and $67.06 \%$ of students respectively. Central nervous system $(19.76 \%)$ and endocrinology $(17.96 \%)$ were two most boring systems. The central $(35.92 \%)$ and autonomic $(31.73 \%)$ nervous systems were two most difficult systems to understand. The combination of lecture notes and textbooks was the preferred reading materials of $58.68 \%$ of students. The most preferred teaching media was the combination of blackboard and chalk with power point presentation $(80.24 \%)$. Increased use of figures, flow charts and diagrams, inclusion of more clinical examples and interactive classes were marked as suggested reforms to enhance the outcome of lecture classes.

Conclusions: This study revealed that students are in favour of a substantial change in the current teaching methodology of pharmacology in place of outdated and useless methods.

Keywords: Pharmacology, Teaching method, Medical students

\section{INTRODUCTION}

Pharmacology is an important subject among basic sciences in the medical curriculum. ${ }^{1}$ It is both a basic as well as an applied discipline of medical science. Pharmacology forms the backbone of rational therapeutics. It involves not only the possession of knowledge but also appropriate application of its knowledge in therapeutics. The biggest impact of pharmacology teaching and learning has to be on calculation of doses, correct prescriptions and rational use of drugs. ${ }^{2}$ The rational use of drugs requires the optimum knowledge of various pharmacokinetic and pharmacodynamic aspects of drugs such as relationship between plasma concentration and toxic effects, plasma half-life, relative efficacy of different drugs, incidence of adverse effects and drug interactions. The ultimate aim of pharmacology teaching in undergraduate medical curriculum is to produce a rational prescriber as a physician of 1 st contact, who can take rational therapeutic decisions in clinical practice. ${ }^{3}$ 
The commonly used teaching-learning methods in pharmacology include lectures, tutorials, practicals and group discussions. Lectures continue to be the dominant method of teaching-learning in medical colleges of India and other developing countries. However, some innovative methods such as problem-based learning (PBL), casebased learning, clinical case presentations and seminars are being exercised by few institutes. ${ }^{4}$ The undergraduate teaching in pharmacology has changed in recent years with adoptions of new methods that focus on supportive learning through novel teaching approaches like small group discussions, role plays, computer assisted learning (CAL), using audio-visual (A-V) aids, clinical pharmacology studies etc. These are being adopted by more and more medical colleges at both the undergraduate and postgraduate levels. ${ }^{5}$

The traditional pharmacology teachings are claimed to be lecture centred that has focused more on factual information with little emphasis on clinical and applied aspects. Pharmacy and experimental practical have been the foundation of practical pharmacology. The utilization and importance of such practical exercises have been the centre of academic debates. ${ }^{6}$ The materials provided through lectures and laboratories seems irrelevant to the practice of clinical medicine. The central themes of pharmacology are better learned in the context of clinical problems. ${ }^{1}$ Therefore, there is a desired shift happening in the pharmacology practical teaching from animal based and pharmacy based redundant experiments to more clinically relevant clinical pharmacology exercises. Clinical pharmacology exercises include rational prescribing, adverse drug reaction (ADR) monitoring, pharmacokinetic calculations, pharmacodynamic toxicity, drug interactions and pharmacotherapeutics. ${ }^{4}$ A seamless progression from basic principles through clinical pharmacology and then on to applied therapeutics has been suggested to be beneficial for medical students regarding proper teaching of pharmacology. ${ }^{7}$

The instructional methods used to teach pharmacology in our institution include lectures, tutorials, and practical sessions such as prescription writing, criticism on rationality of prescriptions, pharmacy practicals and demonstration of experimental pharmacology with CAL using $\mathrm{A}-\mathrm{V}$ aids or using live animals. Lectures are being taken either using black-board and chalks or using power point presentations. The use of overhead projector has been replaced with power point presentations for past few years.

Thus, there seems to be an imbalance in between the need and the existing teaching methodologies for the subject of pharmacology. Modification in teaching methodologies at regular interval is required to overcome such imbalance and to enhance the outcome of teaching-learning activities. Evaluation of learners perception on existing methodologies and their preferences regarding various novel teaching approaches through feedback from students provide an opportunity to assess lacunae in current system and forms the basis for framing desired modifications to develop student centred teaching methods and to enhance the magnitude of learning. ${ }^{8-10}$ Feedback from students on current teaching-learning activities and their views on various novel approaches is thus a desired tool to evaluate their perceptions and preferences and thereby to enhance the outcome of teaching and learning activities. Investigators of this study were unable to get any previous data of this institute on this issue in spite of their all efforts. Therefore, this study was planned with an objective to generate data on the perception of second professional medical students regarding the current teaching-learning activities and their preferences for the novel teachinglearning approaches. The aim of this study also included to generate the subsequent data on suggested modifications to be made in area of current teaching-learning activities, so that they can be employed to enhance the magnitude of learning.

\section{METHODS}

This was a questionnaire based cross-sectional study conducted at department of pharmacology of Jawahar Lal Nehru (JLN) medical college Bhagalpur. The prevalidated questionnaire was used to get the data, which was prepared after the review of literatures of previous studies with some suitable modifications. ${ }^{11-14}$ Apart from the basic demographic information of participating students, the questionnaire consisted of two parts. The perceptive and preference aspects of students were recorded as the answers of twenty questions in part A and the opinion of students for recommended changes in the existing teaching-learning activities were recorded as the answers in yes or no in part B of this questionnaire. There were multiple choice questions (MCQs) having three to nine choices in part A of the questionnaire. Students were given freedom to mark more than one answer for two special questions in part A of the questionnaire. Otherwise, they were instructed to mark only one most appropriate answer for rest of the part A questions. The prior approval of the study was taken from the institutional ethics committee. Students were well explained the purpose of this study before taking their consents for the study. All the students of $3^{\text {rd }}$ and $5^{\text {th }}$ semesters $(n=200)$ of two consecutive batches during their second professional undergraduate medical course were approached for this study in the month of November 2019. However, one student of third semester and seventeen students of $5^{\text {th }}$ semester were excluded on the basis that their questionnaire sheets were incompletely marked. Another 15 students of $5^{\text {th }}$ semester were excluded from the study on the ground that they were not willing to give their consents. The identity of the participating students was kept anonymous. The questionnaire sheets marked in complete manner were received from 167 students and they were critically analysed to get the descriptive data. The number and percentage were used to express the data.

\section{RESULTS}

This study was conducted on a total of 167 students of second professional undergraduate medical course. 
Among them, 99 (59.28\%) were from $3^{\text {rd }}$ semester and 68 $(40.72 \%)$ were from $5^{\text {th }}$ semester. $97(58.08 \%)$ male and $70(41.92 \%)$ female students formed the studied samples. The pharmacology followed by pathology were found to be the most interesting subjects as these were marked by $82(49.1 \%)$ and $70(41.91 \%)$ students respectively. The pharmacology and pathology were marked as two most useful subjects by $112(67.06 \%)$ and $49(29.34 \%)$ students respectively. One hundred $(59.88 \%)$ students were having some information about pharmacology as a subject before their 2nd professional undergraduate medical course. Seventy five $(44.91 \%)$ students acknowledged pharmacology as interesting and useful subject while 73 (43.71\%) students marked this subject as very interesting, useful and practically important. The 75 (44.91\%) students marked that pharmacology is the interesting and useful as per the opinion of their seniors while $56(33.53 \%)$ students marked that the pharmacology is very interesting, useful and practically important in opinion of their seniors. Pharmacology was considered as one of the subjects for postgraduation only by $28(16.76 \%)$ students. One hundred and twenty six students $(75.44 \%)$ were not sure to consider pharmacology as a choice for their postgraduation.

The autonomic nervous system (ANS) followed by the cardiovascular system (CVS) were marked as two most interesting systems by $38.32 \%$ and $22.75 \%$ of students respectively. The central nervous system (CNS) and endocrine system were marked as two most boring system by $19.76 \%$ and $17.96 \%$ of students respectively. The analysis of perception of students for various systems of pharmacology has been detailed in Table 1 .

Table 1: Analysis of perception of students for various systems of pharmacology.

\begin{tabular}{|llllll|}
\hline Systems & $\begin{array}{l}\text { Most } \\
\text { interesting }(\%)\end{array}$ & $\begin{array}{l}\text { Most } \\
\text { boring }(\%)\end{array}$ & $\begin{array}{l}\text { Most } \\
\text { easy }(\%)\end{array}$ & $\begin{array}{l}\text { Most } \\
\text { difficult }(\%)\end{array}$ & $\begin{array}{l}\text { Most } \\
\text { rewarding }(\%)\end{array}$ \\
\hline Gen. pharma. & $21(12.57)$ & $19(11.37)$ & $46(27.54)$ & $07(4.19)$ & $32(19.16)$ \\
\hline ANS & $52(31.13)$ & $23(13.77)$ & $15(8.98)$ & $53(31.73)$ & $54(32.33)$ \\
\hline CVS & $43(25.74)$ & $10(5.98)$ & $14(8.38)$ & $18(10.77)$ & $54(32.33)$ \\
\hline CNS & $04(2.39)$ & $33(19.76)$ & $00(00)$ & $60(35.92)$ & $08(4.79)$ \\
\hline GIT & $14(8.38)$ & $07(4.19)$ & $32(19.16)$ & $00(00)$ & $01(0.59)$ \\
\hline Respiratory & $16(9.58)$ & $03(1.79)$ & $28(16.76)$ & $02(1.19)$ & $01(0.59)$ \\
\hline Endocrinology & $02(1.19)$ & $30(17.96)$ & $06(3.59)$ & $19(11.37)$ & $03(1.79)$ \\
\hline Chemotherapy/antimicrobials & $12(7.18)$ & $17(10.17)$ & $20(11.97)$ & $03(1.79)$ & $13(7.78)$ \\
\hline Autacoids/NSAIDs & $03(1.79)$ & $25(14.97)$ & $06(3.59)$ & $05(2.99)$ & $01(0.59)$ \\
\hline
\end{tabular}

Ninety eight $(58.68 \%)$ students marked combination of lecture notes and text books as their preferred reading materials, whereas $50(29.94 \%)$ students were favour of combination of lecture notes, textbooks, self-made notes and small handy books all as their preferred reading materials. One hundred and seventeen $(70.06 \%)$ students marked the one and half year as adequate period for pharmacology teaching. Only $34(20.36 \%)$ students were in favour that one year is adequate for teaching of pharmacology. Group discussion was marked by 98 $(64.67 \%)$ students as best teaching method and tutorials was marked by $45(20.96 \%)$ students (Figure 1$)$.

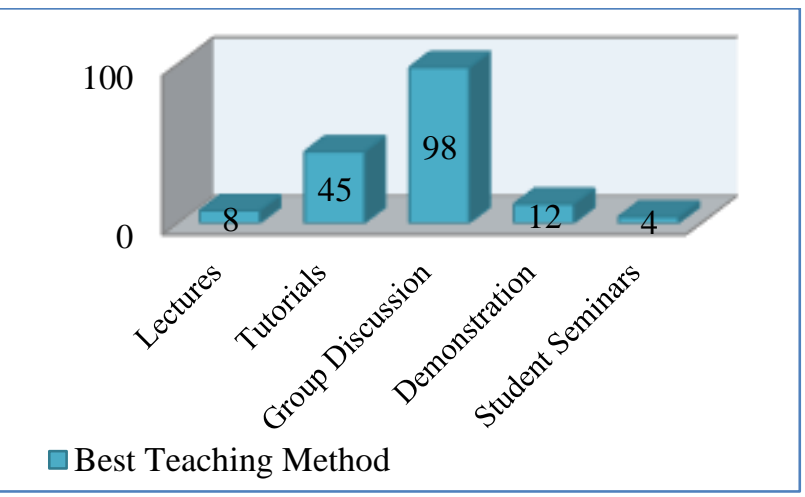

Figure 1: Preference of students for various teaching methods.
Prescription writing was marked as the most useful part of practical classes by $91(54.49 \%)$ students whereas the pharmacy practical was marked as most useless part of practical classes by $57 \quad(34.13 \%)$ students. The combination of chalk and black board along with use of power point presentations was preferred by $134(80.24 \%)$ students. The perception regarding the use of teaching media is depicted in Figure 2.

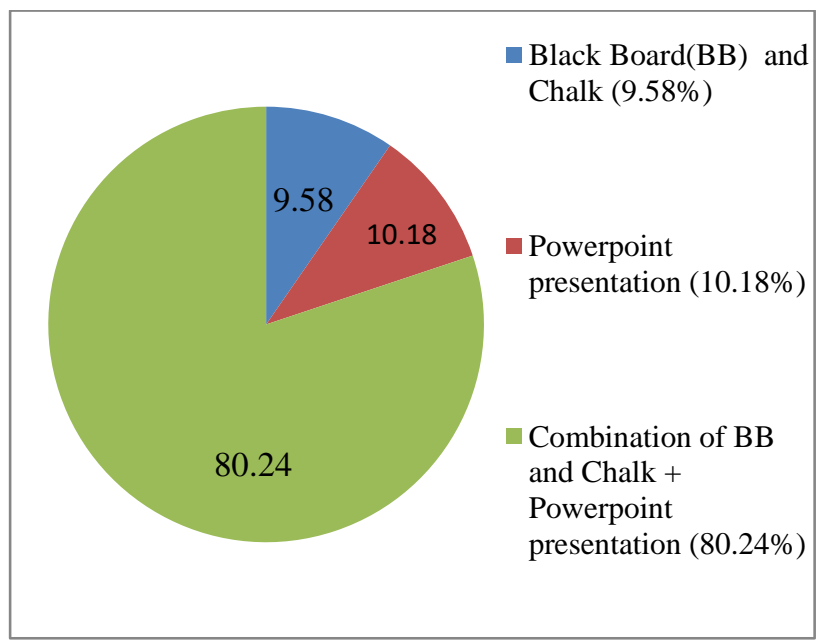

Figure 2: Perception of students regarding ideal teaching media. 
Table 2: Opinion of students on changes recommended.

\begin{tabular}{|lll|}
\hline $\begin{array}{l}\text { Opinion } \\
\text { Make more use of A-V }\end{array}$ & $\begin{array}{l}\text { Response } \\
\text { in 'yes' }\end{array}$ & $\begin{array}{l}\text { Response } \\
\text { in 'no' }\end{array}$ \\
$\begin{array}{l}\text { aids } \\
\text { Increase the no. of } \\
\text { lectures }\end{array}$ & 58 & 35 \\
\hline $\begin{array}{l}\text { Introduce PBL } \\
\text { Introduce group } \\
\text { discussions }\end{array}$ & 157 & 109 \\
\hline $\begin{array}{l}\text { Introduce more clinical } \\
\text { pharmacology and } \\
\text { pharmacovigilance }\end{array}$ & 156 & 11 \\
\hline $\begin{array}{l}\text { Introduce recent } \\
\text { advancement in lecture } \\
\text { classes }\end{array}$ & 159 & 14 \\
\hline $\begin{array}{l}\text { Introduce calculation of } \\
\text { pharmacokinetic } \\
\text { parameters like Vd, t } \mathbf{1} \text { /2, } \\
\text { Cpss in practical classes } \\
\text { and assessment methods }\end{array}$ & 127 & 08 \\
\hline
\end{tabular}

The multiple-choice questions (MCQs) and short answer question (SAQs) were liked individually by $18(10.77 \%)$ and $14(8.38 \%)$ students respectively as tool for proper assessment in examinations. Only 2 students liked the long answer questions (LAQs) alone and 133 students (79.64\%) preferred the combination of all sorts of questions (MCQs+SAQs+ LAQs) for proper assessment in examinations. Increased use of flow charts, figures and diagrams along with inclusion of more clinical examples and more interactive classes were marked 117, 98 and 82 times respectively by students as reforms suggested to increase the outcome of lecture classes. More emphasis on prescription writing, demonstration of experimental practical using CAL software and demonstration of drug administration methods using manikins were marked 57, 69 and 74 times respectively as suggested reforms to increase the outcome of practical classes by the students. Most of the recommendations regarding change to be made in the current systems were answered in yes by more than $75 \%$ students except that $65.26 \%$ students disfavoured the increase in number of lecture classes. The details of opinion about changes recommended by students are provided in the Table 2.

\section{DISCUSSION}

The health of the society depends largely on the medical education system. This system therefore requires the best teachers and the teaching methods that can produce the best medical practitioners from the medical students. ${ }^{14}$ Effective teaching involves adopting appropriate teaching roles to support learning goals. ${ }^{15}$ There is a close association between the student's opinion and the instructor's effectiveness. ${ }^{16}$ Feedback from students enables us to know their perception and preferences and is an effective tool in developing teaching and evaluation methodology. ${ }^{17}$

Feedback from students on various aspects of pharmacology teaching were taken in our study and it was found that the pharmacology is not only the most interesting (49.1\%) but also the most useful $(67.06 \%)$ subject during second professional undergraduate medical course. This particular subject was declared as interesting and useful both in the opinion of participants as well as their seniors (44.91\% each). This subject was declared very interesting, useful and practically important in the opinion of $33.53 \%$ of participants and $43.71 \%$ of their seniors. This subject was found to be interesting, useful and practically important also by $43 \%$ of participating students in a similar study conducted by Rani et al and by $72.38 \%$ of those in study of Chavda et al. ${ }^{9,12}$ These figures signify the importance of pharmacology as a subject of second professional undergraduate medical course. The teaching of pharmacology therefore requires special attention to make it efficient, taking care its usefulness and importance.

Pharmacology was considered as one of the subjects for postgraduation only by $16.76 \%$ students in our study. Manjunath et al reported that only $10 \%$ students wished pharmacology as one of the subjects for their postgraduation. ${ }^{13}$ Student's perception in this regard seems to be biased towards clinical subjects rather than the basic sciences subjects. Perhaps they think that there are more opportunities for career and earning in clinical subject's field. The career and earning opportunities as pharmacologist in the various fields including those in pharmacovigilance and clinical research must be highlighted to students to minimize the bias.

The central nervous system $(19.76 \%)$ and the endocrine system $(17.96 \%)$ were found to be most boring. An attempt to make these topics interesting must be taken by the faculties of the department. The central (35.92\%) and autonomic $(31.73 \%)$ nervous systems were found to be most difficult to understand in our study. A multidirectional effort must be made by the department to make these topics easy to understand. The autonomic nervous system and cardiovascular system (32.33\% each) apart from general pharmacology $(19.16 \%)$ were found to be most rewarding and useful topics for the future life of students in our study. These topics want due attention and emphasis both by the teachers and the students in the classes.

Lecture notes in combination with text books were preferred reading materials of $58.68 \%$ of students in our study. Garg et al in a similar study reported that $75 \%$ students preferred the combination of lecture notes and textbooks. ${ }^{11}$ Mehta et al also reported the same trend regarding preferred reading material of students in a similar study. ${ }^{14}$ This signifies the importance of lectures and an attempt must be made by concerned faculties to enhance the interest and outcome of such classes. The 
interest in lecture classes can be increased by making classes more interactive, using more diagrams, flow charts, figures and inserting more clinical examples in the classes as these are also the reforms suggested to enhance the interest and outcome of lecture classes by majority of our students. The outcome of lecture classes can be improved also by providing the teacher's note or hands out at the end of lectures.

One and half year was claimed to be the adequate period for pharmacology teaching by $70.05 \%$ of students and only one year was accepted as adequate period by only $20.35 \%$ students in our study. The one and half year was considered as an ideal period to learn second MBBS by majority of students also in a similar study conducted by Rani et al, Chavda et al and Mehta et al by $64.3 \%, 55.14 \%$ and $60 \%$ of students respectively..$^{9,12,14}$ The concerned authority should reconsider the adequacy of one year as period for pharmacology teaching taking into account the student's perception.

The preferred teaching methods in our study were group discussion (58.68\%) and tutorials (26.94\%). Group discussion $(25.33 \%)$ and tutorials( $28 \%$ ) were preferred as the best teaching methods also in the study conducted by Mukku et al. ${ }^{18}$ Group discussion and tutorial classes are usually conducted with small group of students where they get the more opportunity to interact with teacher and to clear their doubts. ${ }^{3}$ Lectures were the most preferred teaching method of $28.7 \%$ students in the study carried out by Vinaya et al. ${ }^{8}$ Lectures and demonstration were preferred teaching methods in study conducted by Jaiswal et al by $41.58 \%$ and $17.45 \%$ of students respectively. ${ }^{3}$ These methods were liked only by $4.79 \%$ and $7.18 \%$ of students respectively in our study. Lectures and seminars were underscored as teaching methods also in the study of Badyal et al. ${ }^{2}$ The reason for disinterest in lectures in our and other studies requires to be sought. Less organized lectures taken with less interaction with students along with fast pace of lectures might be among the possible reasons.

The combined use of blackboard and chalk with the power point presentation were found to be the preferred teaching media by $80.24 \%$ of students in our study. This is in accordance with reports of similar other studies. ${ }^{13,14,18-22}$ Students preferred different media of teaching for different purposes in a study conducted at Delhi. It was suggested in this study that the lecture could best be a combination of two or more teaching-learning media. ${ }^{23}$ Each medium has its own merits and demerits. More opportunities of interaction with teachers, least chance to induce sleep and best recall capability are merits of blackboard teaching and more coverage of subject matter, legible words, wellstructured diagrams, point wise presentation of information and smart looking slides are that with power point presentations. The demerits of using blackboard and chalk are poor handwritings, complexity of drawing diagrams, less covering of subject matter and dirty looking blackboards, whereas that of power point presentations are quick delivery of lectures, too much materials, less opportunity for interaction and sleep induction. ${ }^{23,24}$ The power point presentation or the use of blackboard and chalk alone were accepted as ideal teaching medium only by $10.18 \%$ and $9.58 \%$ of students respectively in our study. Thus, both of these methods used alone were disfavoured by majority of students. This might be due to demerits of these methods used individually. The combination of these methods minimizes these demerits and maximizes the merits of both the media. Our findings in this concern contradicts the report of Subash and Baruah et al that the power point presentation is preferred over the other medias of teaching. ${ }^{10,25}$ Thus our study and majority of other studies suggest the combined use of blackboard and chalk along with power point presentation as the ideal teaching method to be adopted.

The most useful part of practical class in our study was found to be the prescription writing by $54.49 \%$ of students. The prescription writing was the most useful and interesting part of pharmacology practical also in the study of Rani et al and Chavda et al. ${ }^{9,12}$ Some previous studies support that teaching to prescribe rationally should be an important part of clinical pharmacology. ${ }^{26,27}$ Students in our study also suggested giving more emphasis on prescription writing as reforms. We recommend therefore giving emphasis on the development of skill of rational prescribing in students. The compact disk (CD) containing CAL software for teaching animal experiments has been proved to be a revolution in pharmacology teaching. It is helpful in teaching pharmacology by simulating action of drugs on receptors and animal tissues without requiring sacrifices of live animals. ${ }^{2}$ Most of our students also suggested demonstrating the experimental part of practical pharmacology using CAL software in lieu of that on live animals. Other reform suggested by most of the students in our study to enhance the outcome of practical classes were demonstration of drug administration methods using manikins. These suggestions are to be welcomed and incorporation of suggested modes of practical is to be promoted. Pharmacy practicals were marked as most useless part of practical sessions by $34.13 \%$ students in our study. Continuation of this part of practical in pharmacology teaching can be omitted taking care its irrelevance in the present scenario.

For proper assessment in examination, the combination of MCQs, SAQs and LAQs were suggested as an appropriate tool in our study by majority $(79.64 \%)$ of students. This is in contradiction to the study report of Subash, where $92 \%$ of students preferred only MCQ's as an instrument for assessment. $^{10}$

Most of our students (94\%) recommended the incorporation of PBL in pharmacology teaching because there is an active participation of every student in PBL sessions and the impact of such sessions on learning remains long standing. This emphasizes the development of problem-solving skills of students rather than memorization. This also aims at learning in a collaborative 
group centred environment. Majority of students in our study were in favour of incorporation of group discussion $(93.41 \%)$, clinical pharmacology exercises including that on pharmacovigilance $(91.61 \%)$, recent advancement $(95.2 \%)$, more use of audio-visual aids (79.04\%) and calculation of pharmacokinetic parameters $(76.04 \%)$ as innovative approaches to be adopted. The reason behind the inclination of students for group discussion lies in the fact that the small group enables them to bring the problems to a platform, where the problems can be shared with peers and can be solved by trying out different approaches. ${ }^{5}$ The use of $\mathrm{A}-\mathrm{V}$ aids as media of teachinglearning is getting common as it enhances successful communication and cuts presentation time. ${ }^{28,29}$

\section{CONCLUSION}

This study reveals that though pharmacology is an interesting and useful subject, students are inclined more towards clinical subjects for their post-graduation. There is a need of substantial change in the current teaching methodology. The combined use of blackboard and chalk along with judicious use of power point presentation is the best method of teaching. Pharmacy practical and demonstration of experimental pharmacology on live animals can be omitted. Students are in the favour of clinically oriented teaching of pharmacology with novel approaches like PBL, group discussions, CAL and demonstration of administration of drugs using manikins.

\section{ACKNOWLEDGEMENTS}

We are grateful to our second professional students for their participation with keen interest for this study. We express our thanks to Mr. Sangam Samrat of our department for his technical assistance provided during the preparation of this manuscript.

\section{Funding: No funding sources}

Conflict of interest: None declared

Ethical approval: The study was approved by the Institutional Ethics Committee

\section{REFERENCES}

1. Rangachari PK. Basic sciences in an integrated medical curriculum: the case of pharmacology. Adv Health Sci Edu. 1997;2(2):163-71.

2. Badyal DK, Bala S, Kathuriya P. Student evaluation of teaching and assessment methods in pharmacology. Indian J Pharmacol. 2010;42(2):86-8.

3. Jaiswal KM, Pimpalkhute SA, Sontakke SD, Bajait CS, Gaikwad A. Evaluation of student`s opinion about current teaching techniques in pharmacology. Int $\mathrm{J}$ of Pharmc Res. 2015;5(3):155-9.

4. Badyal DK. Evolution of pharmacology education in India: Past and future. Indian $\mathbf{J}$ Pharmacol. 2018;50:159-68.
5. Sharma R, Verma U, Kapoor B, Chopra VS. Novel teaching approaches in pharmacology. JK Science. 2004;6(3):172-3.

6. Desai M. Changing face of pharmacology practicals for medical undergraduates. Indian J Pharmacol. 2009;41(4):151-2.

7. Routledge PA. The interface between clinical and laboratory pharmacology. $\mathrm{Br} \mathrm{J}$ Clin Pharmacol. 1999;47:611-2.

8. Vinaya M, Podder S, Pradhan G. Learning styles and teaching-learning method preferences of second year medical undergraduates in pharmacology in a rural medical college. Int J of Pharmc Res. 2015;5(4):2036.

9. Rani V, Tekulapally K, Padmavathi V, Simpson GB. Second year medical students' perception about pharmacology and teaching methodologies used: A questionnaire based cross sectional study. Indian J Basic Appl Med Res. 2016;5(4):238-45.

10. Subash KR. "Likes and dislikes"-A questionnairebased analysis and feedback from medical school learners. Int J of Pharmc Res. 2014;4(4):173-5.

11. Garg A, Rataboli PV, Muchandi K. Student`s opinion on the prevailing teaching methods in pharmacology and changes recommended. Indian $\mathbf{J}$ Pharmacol. 2004;36(3):155-8.

12. Chavda N, Yadav P, Chaudhari M, Kantharia ND. Second year student's feedback on teaching methodology and evaluation methods in Pharmacology. Natl J Physiol Pharm Pharmacol. 2011;1:23-31.

13. Manjunath SM, Nagesh RG, Srinivas TR, Someswara GM. A study on the evaluation of medical student's perception and feedback of teaching-learning of pharmacology in a medical college. Int Arch Integr Med. 2015;2(9):102-10.

14. Mehta M, Adwal S, Chourishi A. Evaluation of different teaching-learning methods according to student's preference and perception. Int J Basic Clin Pharmacol. 2017;6:76-9.

15. Tripathi R, Kumar A. Importance and improvements in Teaching-Learning process through effective evaluation methodologies. Int J Env Rehab Conserv. 2018;IX(1/2):7-16.

16. Dash SK, Patro S, Behera BK. Teaching methods and its efficacy, an evaluation by the students. J Indian Acad Forensic Med. 2013;35(4):321-4.

17. Karan J, Chavda N, Yadav P, Kanthuria ND. Intern doctors' feedback on teaching methodologies in pharmacology. J Pharmacol Pharmacother. 2010;1:114-6.

18. Mukku LS, Alla J, Rachamanti R. Medical student`s perception on teaching-learning methods of pharmacology in a medical college. Int $\mathbf{J}$ Basic Clin Pharmacol. 2018;7:665-8.

19. Padmanabha TS, Manu G, Kulkarni GP, Chandrakantha T, Neha K. A prospective study of perceptions and preferences of medical students regarding teaching aids in teaching Pharmacology in 
a Medical College from India. Sch J App Sci. 2016;4(6C):2084-8.

20. Vare VA, Kurle DG, Bagle TR, Hire RC, Shukla AO. Evaluation of teaching methods in pharmacology among MBBS students. Int J Basic Clin Pharmacol. 2017;6:1352-7.

21. Bandyopadhyay D. A study on the evaluation of perception of teaching-learning methods of pharmacology among the $2^{\text {nd }}$ M.B.B.S. students in Burdwan Medical College, West Bengal, India. Reviews of Progress. 2012;1(12):1-11.

22. Mishra R, Mondal A. Attitude of undergraduate medical students towards power point, overhead projector and chalk board teaching methods in north India. Int J of Pharmc Res. 2015;5(2):61-4.

23. Dhaliwal U. A prospective study of medical students perspective of teaching-learning media: Reiterating the importance of feedback. J Indian Med Assoc. 2007;105(11): 621-3.

24. Shallcross DE, Harrison TG. Lectures: electronic presentations versus chalk and talk-a chemist's view. Chem Educ Res Pract. 2007;8(1):73-9.
25. Baruah M, Patel L. Evaluation of different teaching methods used in physiology lectures. Indian J Basic Appl Med Res. 2014;4(1):271-6.

26. Han WH, Maxwell SR. Are medical students adequately trained to prescribe at the point of graduation? Views of first year foundation doctors. Scott Med J. 2006;51:27-32.

27. Heaton AI, Webb DJ, Maxwell SR. Undergraduate preparation for prescribing: the views of $2413 \mathrm{UK}$ medical students and recent graduates. $\mathrm{Br} \mathrm{J}$ Clin Pharmacol. 2008;66:128-34.

28. Rieder CE. Guidelines for a scientific presentation. J Prosthet Dent. 1992;68:702-7.

29. Fishman M. Presentation of audio-visual aids for infection control education. Am J Infect Control. 1984; $12: 10-3$.

Cite this article as: Kumar J, Pandit MK, Anand P, Kumar B. Perception and preferences of second professional undergraduate medical students for pharmacology teaching: a questionnaire based crosssectional study. Int J Basic Clin Pharmacol 2021;10:1069-75. 